\title{
Usinagem
}

\section{Efeito do nitrogênio na usinabilidade do aço inoxidável austenítico: uma avaliação utilizando a técnica da esclerometria pendular instrumentada}

\author{
André Paulo Tschiptschin \\ Departamento de Engenharia Metalúrgica e de Materiais - Escola Politécnica USP. E-mail: antschip@usp.br \\ Carlos Mario Garzón \\ Universidad Nacional de Colombia. Departamento de Física, sede Bogotá. E-mail: cmgarzono@unal.edu.co \\ Diana Maria Lopez \\ Departamento de Engenharia Metalúrgica e de Materiais - Escola Politécnica USP.E-mail: dmlopez@usp.br
}

\section{Resumo}

Os aços inoxidáveis de alto teor de nitrogênio constituem hoje uma classe promissora de materiais de engenharia. Quando se adiciona nitrogênio aos aços austeníticos, consegue-se aumentar, simultaneamente, a vida em fadiga, a resistência mecânica, a resistência ao desgaste e à corrosão. Nesse trabalho, estudam-se a resistência ao desgaste e a usinabilidade de um aço inoxidável austenítico UNS S30403 nitretado em alta temperatura. A nitretação gasosa em alta temperatura $\left(1200^{\circ} \mathrm{C}\right)$ em atmosferas $\left(\mathrm{N}_{2}+\mathrm{Ar}\right)$ foi realizada para obter amostras com teores crescentes de nitrogênio na superfície, desde 0,05 até aproximadamente $0,45 \%$ em peso. Os ensaios de esclerometria foram realizados em um pêndulo instrumentado de um único passe, com possibilidade de medir as forças normais e tangenciais durante o ensaio. A energia específica absorvida foi calculada através da relação entre a energia absorvida no ensaio e a perda de massa observada no ensaio. Observou-se que o aumento do teor de nitrogênio causou um aumento da energia específica absorvida. Os resultados dos ensaios foram analisados levando em consideração o comportamento da curva tensão deformação desses aços, inferida a partir de ensaios de indentação instrumentada, e da energia absorvida em ensaios de impacto Charpy. $\mathrm{O}$ aumento da resistência ao risco e a diminuição da usinabilidade devida à adição de nitrogênio foram atribuídos ao forte efeito endurecedor do nitrogênio em solução sólida, sem afetar, significativamente, a taxa de encruamento e a tenacidade.

Palavras-chave: Aços austeníticos, nitrogênio em aços, resistência ao risco, usinabilidade.

\begin{abstract}
High nitrogen stainless steels (HNSS) are being considered a new promising class of engineering materials. When nitrogen is added to austenitic steels it can simultaneously improve fatigue life, strength and wear and localized corrosion resistance. In this work, a single pass pendulum scratch test was used to study the effect of nitrogen on the scratch resistance and on the machinability of an UNS S30403 austenitic stainless steel. Samples with increasing nitrogen contents at the surface were obtained through high temperature gas nitriding. The thermochemical treatments were performed at $1473 \mathrm{~K}$ in $\left(\mathrm{N}_{2}+\mathrm{Ar}\right)$ gas atmospheres for $36.0 \mathrm{ks}$, obtaining fully austenitic cases (surface nitrogen contents up to $0.5 \mathrm{wt} \%$ ) ca. $1.5 \mathrm{~mm}$ in depth. The scratch tests were performed in a single-pass pendulum, equipped with strain gages to measure normal and tangential forces during scratching. The specific absorbed energy was calculated as the ratio between the measured absorbed energy and the amount of mass removed from the specimen. An increase of the specific absorbed energy with increasing nitrogen content was observed. The results of the scratch tests were analyzed taking into account the stress-strain behavior during depth sensing indentation tests and the energy absorbed during Charpy impact tests. The improvement in scratch resistance due to nitrogen alloying was attributed to the strong hardening effect of nitrogen in solid solution, which does not affect significantly foundry hardening and toughness. A comparison between the scratch resistance and the pitting-erosion resistance, measured in previous work, was made too.
\end{abstract}

Keywords: Austenitic steels, nitrogen in steels, scratch resistance, machinability. 


\section{Introdução}

Os aços inoxidáveis têm sido largamente utilizados em componentes que trabalham em condições corrosivas. O nitrogênio é um importante elemento de liga que aumenta, simultaneamente, a vida em fadiga, o limite de resistência, a resistência à fluência e a resistência à corrosão localizada [1-7]. Essas propriedades são muito importantes, particularmente em aplicações em que o desgaste e a corrosão atuam simultaneamente, como em assentos de válvulas e em próteses de quadril.

A hipótese mais aceita para explicar o efeito benéfico do nitrogênio sobre essas propriedades é a de que promove um aumento do caráter metálico das ligações químicas e promove ordenação de curto alcance em comparação com as soluções sólidas em ligas austeníticas contendo Fe-Cr-Ni-C. [8].

A fabricação desses aços não é trivial devido ao baixo limite de solubilidade do nitrogênio no metal líquido. As rotas de produção dos aços de alto nitrogênio que utilizam metalurgia sob alta pressão, metalurgia do pó, e difusão no estado sólido vêm sendo intensamente estudadas [9-11]. Recentemente foi desenvolvido um tratamento termoquímico de baixo custo, que permite aumentar o teor de nitrogênio na superfície dos aços [6, 11-17], chamado de Nitretação Gasosa em Alta Temperatura (NGAT). Esse tratamento é feito expondo o aço a atmosferas contendo $\mathrm{N}_{2}$ em temperaturas entre 100 e $1200^{\circ} \mathrm{C}$.

Pode-se obter, através desse tratamento, microestruturas austeníticas sem precipitação de nitretos e teores de nitrogênio entre 0,2 to $1,0 \%$ em peso [ 17 19]. Obtêm-se camadas nitretadas com profundidade de 0,5 to $2,0 \mathrm{~mm}$ em tempos de tratamento de 5 a 12,5 horas. O tratamento de nitretação gasosa em alta temperatura é diferente do tratamento de nitretação convencional feito em temperaturas entre 500 e $560^{\circ} \mathrm{C}$, nos quais ocorre intensa precipitação de nitretos aumentando a dureza, mas prejudicando a resistência à corrosão das peças tratadas.
Consegue-se, dessa forma, melhorar o desempenho em desgaste (cavitação, erosão, deslizamento e fretting) e a resistência à corrosão localizada (por pites e em frestas) de aços martensíticos, austeníticos e dúplex [5-6, 11-15, 18-19].

Um dos problemas enfrentados, na otimização dos tratamentos termoquímicos mencionados, é a grande quantidade de ensaios para avaliar as relações processamento, propriedades e desempenho desses materiais. Nesse trabalho, discute-se a possibilidade de usar um pêndulo esclerométrico de único passe para avaliar as propriedades tribológicas e a usinabilidade de aços inoxidáveis austeníticos submetidos a tratamentos termoquímicos NGAT.

A esclerometria pendular instrumentada é uma técnica barata e rápida para avaliar a dureza dinâmica e a resistência à abrasão de diferentes materiais [20-23]. Os ensaios de esclerometria realizados em pêndulos de um único passe estão sendo utilizados para avaliar a usinabilidade dos materiais sem necessidade de realizar ensaios de usinagem em campo, caros e demorados. Paro et al. estudaram a usinabilidade de aços inoxidáveis austeníticos de alto teor de nitrogênio e relataram que o nitrogênio tem um efeito benéfico na usinabilidade desses materiais [24].

O objetivo desse trabalho é estudar o efeito do nitrogênio na resistência ao desgaste por risco de um aço inoxidável austenítico UNS S30403 submetido à nitretação gasosa em alta temperatura, usando um ensaio de esclerometria pendular de único passe.

Tabela 1 - Composição química do aço inoxidável austenítico UNS S30403 (\% em peso).

\begin{tabular}{c|c|c|c|c|c|c}
\hline $\mathbf{C r}$ & $\mathbf{N i}$ & $\mathbf{M n}$ & $\mathbf{S i}$ & $\mathbf{M o}$ & $\mathbf{C}$ & $\mathbf{T i}$ \\
\hline 18,1 & 8,5 & 1,3 & 0,5 & 0,04 & 0,025 & 0,0056 \\
\hline
\end{tabular}

\section{Materiais e métodos Nitretação gasosa em alta temperatura}

As amostras para ensaios de dureza, resistência ao desgaste e ensaios de impacto foram usinadas a partir de uma chapa grossa, com $6 \mathrm{~mm}$ de espessura, de aço inoxidável austenítico UNS S30403 laminado a quente. A composição química do aço encontra-se na Tabela 1.

Quatro conjuntos de amostras foram nitretados em alta temperatura para obter diferentes teores de nitrogênio na superfície. Uma série de amostras foi, simplesmente, solubilizada para comparar os aços nitretados com aços não submetidos à nitretação $(0,02 \% \mathrm{~N})$.

Os tratamentos de nitretação foram feitos em forno tubular a $1200^{\circ} \mathrm{C}$, sob pressão de 0,13 MPa e, as amostras expostas a atmosferas contendo $\left(\mathrm{Ar}+\mathrm{N}_{2}\right)$, durante 10 horas sob pressões parciais de 0,02, 0,05, 0,1 e 0,17 MPa $\mathrm{N}_{2}$. As amostras foram, em seguida, temperadas em água. Já as amostras de aço não nitretado foram solubilizadas em temperaturas e durante tempos iguais aos dos ciclos de nitretação.

\section{Esclerometria pendular de passe único}

Amostras, na forma de prisma retangular (6 mm $\times 9 \mathrm{~mm} \times 55 \mathrm{~mm})$, foram polidas metalograficamente com pasta de diamante até $1 \mu \mathrm{m}$. Em seguida, foram submetidas ao ensaio de esclerometria pendular de único passe (ensaio de risco) em um pêndulo Charpy modificado de $50 \mathrm{~J}$ de capacidade. A ferramenta de risco foi confeccionada em metal duro na forma de pirâmide de base quadrada com ângulo de $40^{\circ}$ e uma face horizontal quadrada de $0.5 \times 0.5 \mathrm{~mm}$ no topo. 
A altura inicial de lançamento do pêndulo foi ajustada para trabalhar com uma energia acumulada de $35 \mathrm{~J}$, resultando em uma velocidade de riscamento no início do contato entre a ferramenta e a amostra de 3,16 m/s. A profundidade dos riscos foi controlada por meio de ajuste vertical do porta-amostras e ajustada para $105 \mu \mathrm{m}$. Quatro riscos foram feitos em cada uma das duas amostras obtidas para cada condição de tratamento termoquímico.

A energia absorvida (E) foi medida com precisão de 0,01 J. A massa removida $(W)$ foi medida em uma balança Scientech SA120 com precisão de 0,1 mg.

A energia absorvida específica (e) - energia consumida durante a remoção de $1 \mathrm{~g}$ de material - foi calculada a partir da energia absorvida (E) e massa removida (W), usando a equação (1) [20].

$e=\frac{E}{W}$

O pêndulo foi, também, instrumentado com "strain gages" para medir as forças normais e tangenciais desenvolvidas durante o ensaio.

\section{Ensaios de Impacto Charpy}

Corpos-de-prova entalhados, de tamanho reduzido ( 5 x 10 x $50 \mathrm{~mm}$ ), foram ensaiados a $27^{\circ} \mathrm{C}$, em uma máquina de ensaio de impacto de $300 \mathrm{~J}$, de acordo com a norma ASTM E23. A profundidade do entalhe foi de $2 \mathrm{~mm}$. Foram ensaiadas três amostras, para cada condição de tratamento termoquímico.

\section{Caracterização das amostras}

As amostras foram analisadas utilizando microscopia óptica e microscopia eletrônica de varredura. Utilizou-se microscópio eletrônico de varredura Philips XL30, para observar as superfícies riscadas e os cavacos. O teor de nitrogênio das amostras nitretadas foi analisado por espectrometria WDS de raios X, em equipamento Oxford WDX600.

As propriedades mecânicas das amostras nitretadas foram medidas na superfície de amostras retangulares (6x $10 \times 10 \mathrm{~mm})$, em um equipamento de indentação instrumentado, Fisherscope H100, com penetrador Vickers. A carga máxima utilizada foi de $250 \mathrm{mN}$, o tempo de carregamento e descarregamento foi de 90 s e o tempo de manutenção da carga máxima foi de 20 s. Os dados obtidos nos ensaios de indentação foram analisados usando o método proposto por Oliver e Pharr [25]. Cada ponto é uma média de onze medidas. Foram analisados a dureza $(\mathrm{H})$, o trabalho total de indentação ( $\left.W_{t}\right)$, o trabalho de indentação irreversível $\left(\mathrm{W}_{\mathrm{ir}}\right)$, o trabalho de indentação reversível $\left(\mathrm{W}_{\mathrm{e}}\right)$, a taxa de carregamento $\left(\mathrm{S}_{1}\right)$, a taxa de descarregamento $(\mathrm{S})$ e o coeficiente de encruamento (n). O coeficiente $n$ foi calculado usando uma função de correção $f$ (n) [26], no procedimento de Oliver e Pharr, para utilização de um penetrador Vickers, conforme equação 2:

$f(n)=1.202-0.857 n+0.302 n^{2}=\frac{S_{1}}{S} \frac{W_{t}}{W_{e}}$

\section{Resultados \\ Caracterização das amostras tratadas}

Tanto a amostra solubilizada quanto as amostras nitretadas apresentaram microestruturas austeníticas livres de precipitados. A profundidade da camada nitretada, determinada através de curvas de microdureza, variou entre 1,2 e 1,6 mm.

A Tabela 2 mostra os resultados dos ensaios de indentação, análise química WDS e energia absorvida no ensaio de impacto.

O teor de nitrogênio na superfície das amostras cresce com o aumento da pressão parcial de nitrogênio. Pode-se observar um forte efeito endurecedor do nitrogênio em solução associado a um efeito fraco de aumento do coeficiente de encruamento (n) e do índice de dutilidade expresso pela relação $\mathrm{W}_{\mathrm{ir}} / \mathrm{W}_{\mathrm{t}}$. Aumentando o teor de nitrogênio até $0,5 \%$, aumenta a dureza de 2,05 para 3,2 GPa e diminui n de 0,155 para 0,130, $\mathrm{W}_{\mathrm{t}}$ de 185.1 para 156.4 nJ e $\mathrm{W}_{\mathrm{ir}} / \mathrm{W}_{\mathrm{t}}$ de 0.899 para 0.854 .

As amostras Charpy de ensaio de impacto sofreram deformação plástica macroscópica, antes de fraturar de maneira $100 \%$ dútil. A Tabela 2 mostra que os aços nitretados, em alta temperatura, não tiveram piora sensível de resistência ao impacto, em relação ao aço UNS S30403 não nitretado; o aumento do teor de nitrogênio diminuiu a resistência ao impacto de 171.5 para $159 \mathrm{~J}$.

\section{Resistência ao riscamento}

A Figura 1 mostra os valores médios dos parâmetros analisados durante os ensaios de riscamento: energia absorvida (E), perda de massa (W), energia absorvida específica (e), máxima força normal $\left(\mathrm{N}_{\mathrm{F}}\right)$ e a relação entre a força tangencial e a força normal $\left(\mathrm{T}_{\mathrm{F}} / \mathrm{N}_{\mathrm{F}}\right)$. A Figura 2 mostra a curva força-distância de riscamento bem como a relação $T_{F} / N_{F}$ durante o evento de riscamento para cada um dos tratamentos estudados.

A energia específica absorvida aumenta com o aumento do teor de nitrogênio, enquanto a energia absorvida e a perda de massa diminuem. Quando o teor de nitrogênio aumenta, a perda de massa, por remoção de material, diminui mais rapidamente do que a energia absorvida, levando a um aumento da energia absorvida específica.

Pode-se ver, na Figura 1, que a máxima força normal e a relação entre força tangencial e a força normal $\mathrm{T}_{\mathrm{F}} / \mathrm{N}_{\mathrm{F}}$ permane- 
Efeito do nitrogênio na usinabilidade do aço inoxidável austenítico: uma avaliação utilizando...

Tabela 2 - Resultados de análise química WDS, ensaios de indentação e ensaios de impacto.

\begin{tabular}{|c|c|c|c|c|c|c|}
\hline \multirow{2}{*}{$\begin{array}{l}\mathrm{PN}_{2} \\
(\mathrm{MPa})\end{array}$} & \multirow{2}{*}{$\begin{array}{l}\text { Teor de nitrogênio } \\
\text { (\% em peso) }\end{array}$} & \multicolumn{4}{|c|}{ Ensaios de indentação } & \multirow{2}{*}{$\begin{array}{c}\text { Energia absorvida no } \\
\text { impacto }(\mathrm{J})\end{array}$} \\
\hline & & H (GPa) & $\mathbf{n}$ & $W_{t}(n J)$ & $W_{\text {ir }} / W_{t}(n J / n J)$ & \\
\hline 0 & 0 & $2,05^{ \pm 0,10}$ & 0,155 & $185,1^{ \pm 3}$ & 0,899 & $171,5^{ \pm 10}$ \\
\hline 0,02 & $0,05^{ \pm 0,05}$ & $2,25^{ \pm 0,13}$ & 0,145 & $181,5^{ \pm 4}$ & 0,895 & $171,5^{ \pm 15}$ \\
\hline 0,05 & $0,11^{ \pm 0,07}$ & $2,35^{ \pm 0,15}$ & 0,135 & $178,2^{ \pm 4}$ & 0,892 & $165,0 \pm 10$ \\
\hline 0,1 & $0,31^{ \pm 0,05}$ & $2,85^{ \pm 0,10}$ & 0,125 & $165,5^{ \pm 2,5}$ & 0,885 & $159,0 \pm 15$ \\
\hline 0,17 & $0,5^{ \pm 0,07}$ & $3,20 \pm 0,10$ & 0,13 & $156,4^{ \pm 2,5}$ & 0,854 & -- \\
\hline
\end{tabular}
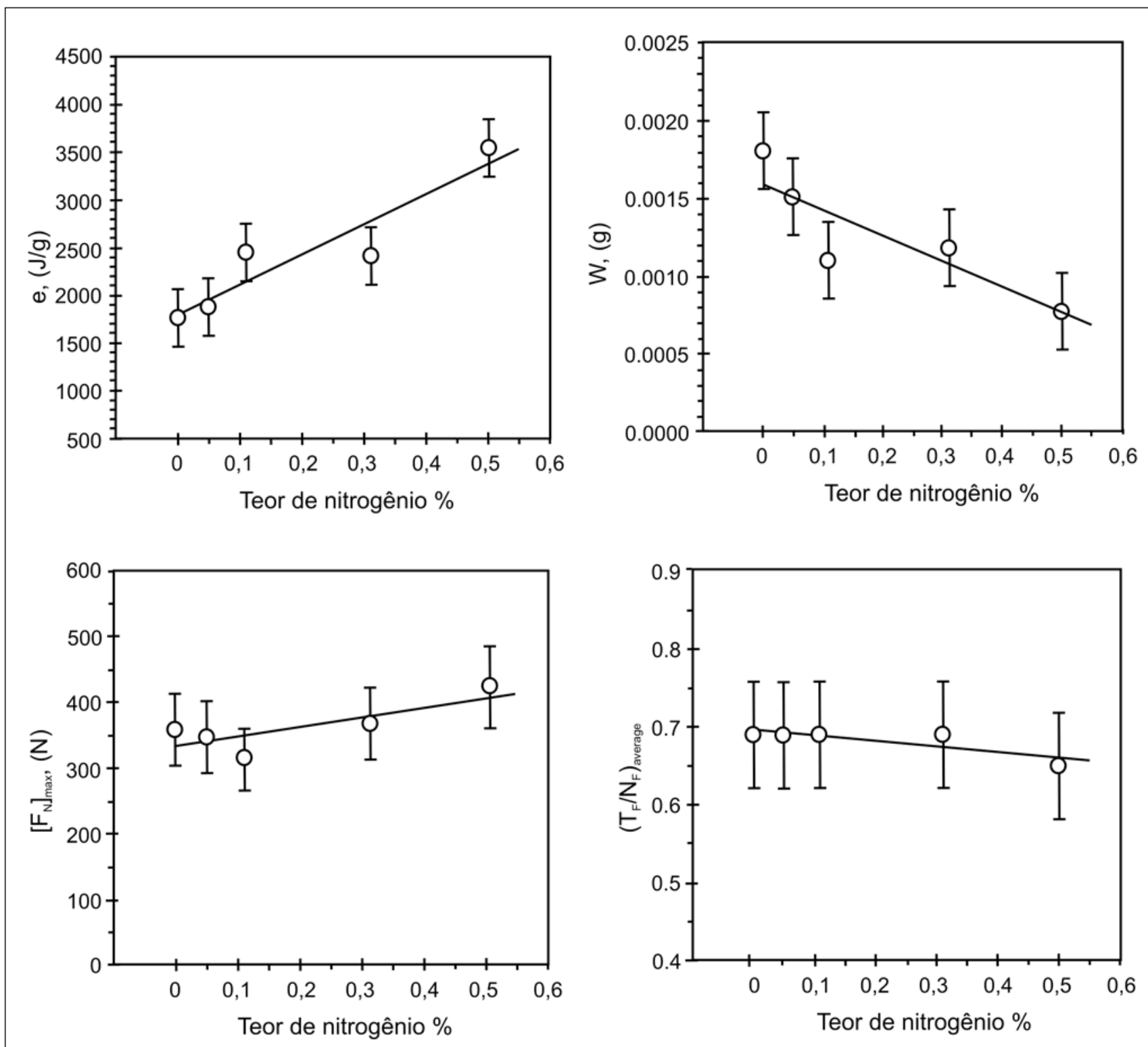

Figura 1 - Efeito do nitrogênio nos resultados obtidos em ensaios de riscamento. 
cem praticamente constantes. A máxima força normal, praticamente, não varia devido à geometria do risco (geometria de ferramenta e profundidade de risco). A máxima força normal é influenciada em menor extensão pelas propriedades plásticas do material.

Por outro lado, a pequena variação de $\mathrm{T}_{\mathrm{F}} / \mathrm{N}_{\mathrm{F}}$ é, principalmente, determinada pelo domínio da componente de sulcamento durante os ensaios: a força tangencial total é igual à soma dos termos de sulcamento de adesão e, para os materiais dúteis, o termo de sulcamento é dominante [27]. Os altos valores dos termos de sulcamento têm sido atribuídos à relativa facilidade com que a profundidade de penetração aumenta com a profundidade imposta no corte [27].

Nas curvas de variação de força $\mathrm{x}$ distância da Figura 2, pode-se observar que a máxima força tangencial ocorre no meio do ensaio de riscamento, onde a profundidade de riscamento é máxima, enquanto a máxima força normal ocorre no último terço da trajetória da ferramenta sobre a amostra. Observa-se, também, uma alta freqüência de oscilação da força tangencial depois do primeiro terço do risco. Essa oscilação é, provavelmente, devida à instabilidade do contato, enquanto a ferramenta sulca a amostra.

Esse comportamento observado em vários outros materiais foi associado a um mecanismo do tipo "stick and slip", em que a ferramenta adere à amostra e em seguida, escorrega sobre a mesma e essa alternância se repete durante algum tempo. [20, 28].

A Figura 3 mostra as superfícies riscadas de duas amostras contendo 0,0 e 0,31 \% N. As paredes do risco no início do riscamento são mais suaves que no meio do risco, onde o mecanismo "stick and slip” ocorre, em consonância com a oscilação de alta freqüência observada na força tangencial, após o primeiro terço de riscamento (Figura 2).

$\mathrm{O}$ aço de mais alto teor de nitrogênio apresenta menor número de rasgamentos e rasgamentos menores que os observados no caso do aço sem nitro-
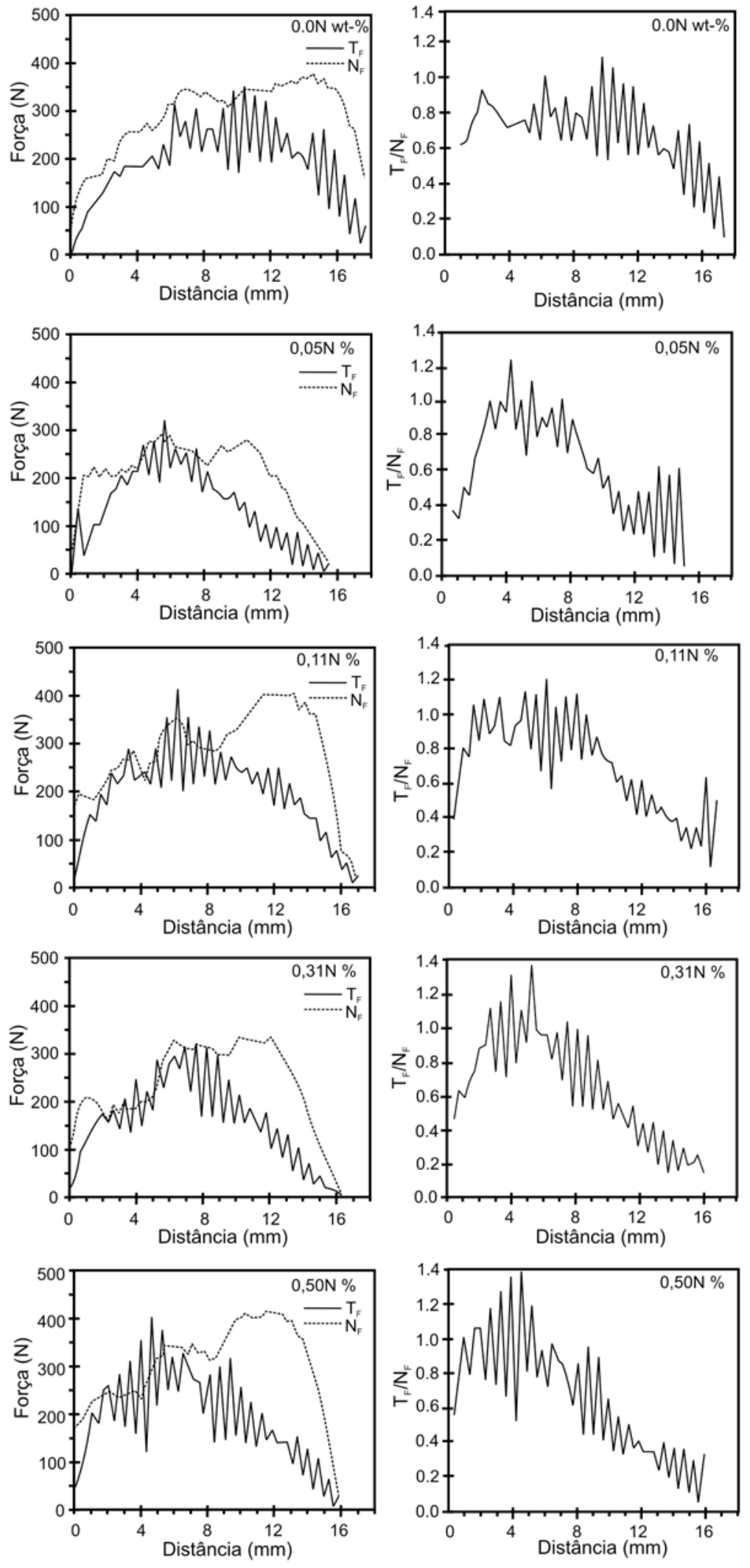

Figura 2 - Variação da força em função da distância em ensaio de riscamento para cada uma das condições de tratamento termoquímico utilizado. 
Efeito do nitrogênio na usinabilidade do aço inoxidável austenítico: uma avaliação utilizando...

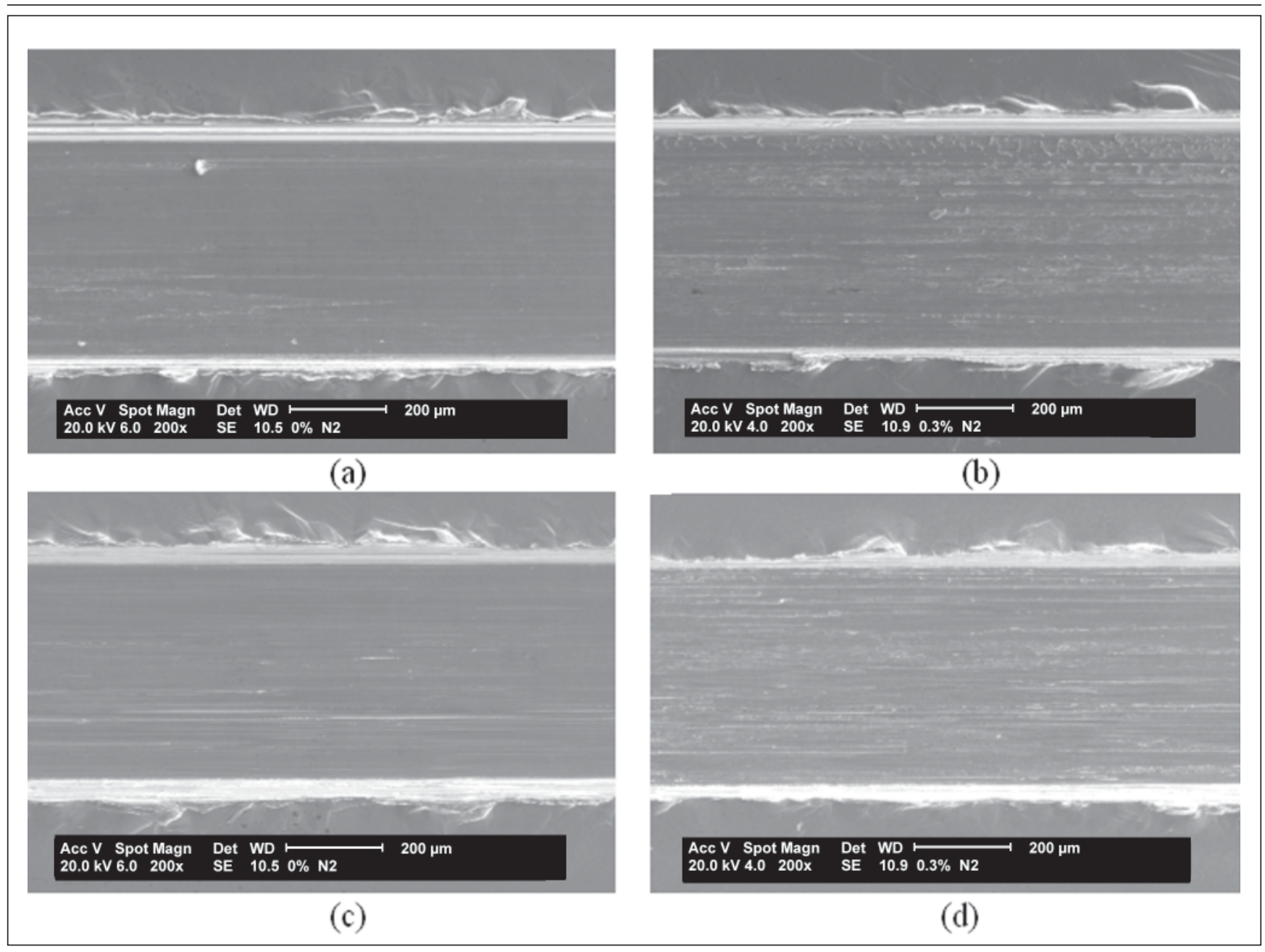

Figura 3 - Imagens das paredes do risco em sua parte inicial (a) e (c), e a meio caminho (b) e (d), para as amostras com 0,0 e $0,31 \% \mathrm{~N}$.

gênio. Na Figura 4, pode-se ver que uma parte do volume de material retirado pela ferramenta foi deslocada para as bordas. Observa-se extensa deformação plástica sem ocorrência de microtrincamento, indicando que o aumento do teor de nitrogênio não fragiliza o material. A remoção de material ocorre, principalmente, por uma combinação dos mecanismos de microcorte e microssulcamento.

\section{Discussão}

Sabe-se que a resposta da superfície de um material ao riscamento envolve recuperação elástica, deformação plástica e desgaste abrasivo por cisalhamento e microtrincamento.

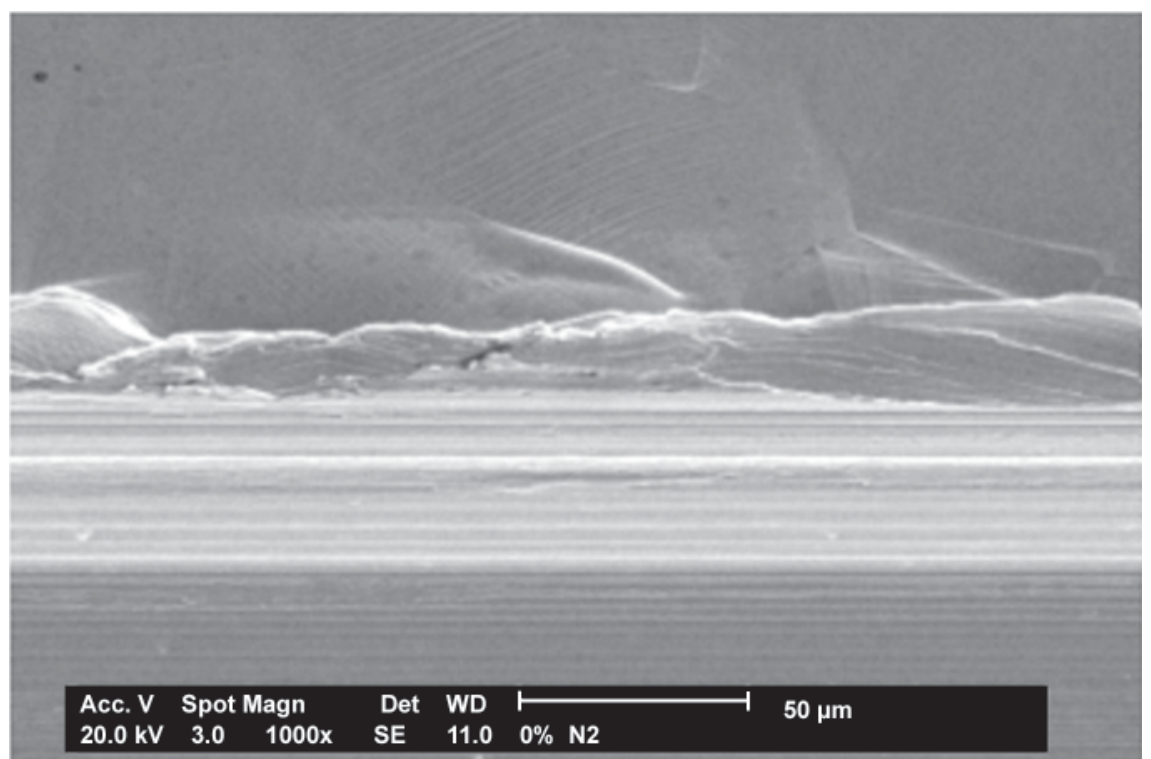

Figura 4 - Imagem de uma região na borda do risco em uma amostra com $0 \% \mathrm{~N}$. Observa-se intensa deformação plástica com linhas de escorregamento e regiões de fratura dútil. 
Os resultados experimentais mostraram que, a despeito do ligeiro abaixamento de tenacidade, provocado pelo aumento do teor de nitrogênio, as fraturas observadas, nos ensaios de risco e nos ensaios de impacto, apresentaram caráter dútil. Além disso, as superfícies nitretadas, com maior teor de nitrogênio, apresentaram maior resistência à deformação plástica associada a uma ligeira diminuição da taxa de encruamento. Assim, o aumento da energia específica absorvida, no ensaio de riscamento, é devida à diminuição do trabalho realizado pela força de contato durante a deformação elasto-plástica do material. Essa hipótese está de acordo com a relação observada, experimentalmente, entre a energia específica e o trabalho de indentação total, durante ensaios de indentação instrumentada, como mostra a Figura 5.

O ensaio de esclerometria pendular de passe único é adequado para avaliar as propriedades de desgaste do aço inoxidável austenítico UNS 30403 nitretado, para diferentes teores de nitrogênio, em solução sólida na austenita. Permite avaliar a energia absorvida específica no ensaio e a usinabilidade (inverso da energia absorvida específica no ensaio de riscamento) desses materiais.

\section{Conclusões}

1. O ensaio de esclerometria pendular de passe único é adequado para avaliar o comportamento tribológico do aço inoxidável austenítico UNS S30403 nitretado com teores de nitrogênio de até 0,5\%.

2. O tratamento de nitretação gasosa em alta temperatura aumenta a resistência ao risco do aço inoxidável austenítico UNS S30403. O aumento do teor de nitrogênio, em solução sólida, até um teor de 0,5\%, leva a um aumento da energia específica absorvida de 1770 para 3540 J/g. Esse efeito pode ser atribuído ao forte efeito endurecedor do nitrogênio em solução sólida, sem que sejam afetadas, significativamente a taxa de encruamento e a tenacidade.

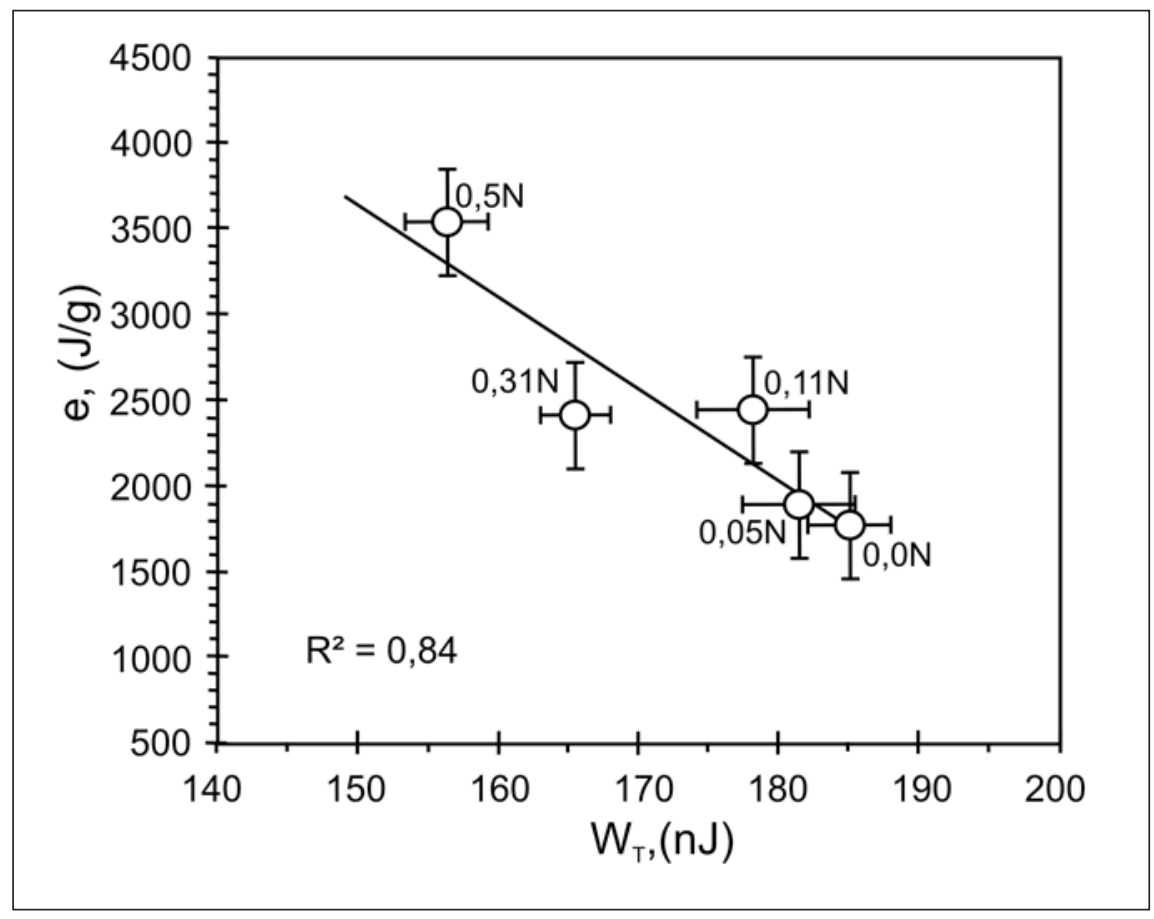

Figure 5 - Relação entre a energia específica absorvida em ensaio de riscamento e o trabalho de indentação total medido em ensaio de indentação instrumentada.

3. A usinabilidade (inverso da energia específica absorvida no ensaio de riscamento) do aço inoxidável austenítico UNS S30403 nitretado diminui com o aumento do teor de nitrogênio.

\section{Referências bibliográficas}

1. GAVRILJUK, V. G. Nitrogen in iron and steel. ISIJ Int. v. 36, n.7, p.738-745, 1996.

2. HÄNNINEN, H., ROMU, J., ILOLA, R., TERVO, J., LAITINEN, A. Effects of processing and manufacturing of high nitrogen-containing stainless steels on their mechanical, corrosion and wear properties. J. Mater. Process Tech. v.117, n. 3, p. 424-430, 2001.

3. TERVO, J. Wear properties of HNS. Mater. Sci. Forum. 318-320: 743-750, 1999.

4. HÄNNINEN H. Corrosion properties of HNS. Mater. Sci. Forum. 318-320: 479488, 1999.

5. BERNS, H., EUL, U., HEITZ, E., JUSE, R. Corrosion behaviour of solution nitrided stainless steels. Mater. Sci. Forum. 318-320: 517-522, 1999.

6. GAVRILJUK, V.G., BERNS, H. High Nitrogen Steels. Berlin: Springer-Verlag, 1999.
7. THOMANN, U., UGGOWITZER, P. Wear-corrosion behavior of biocompatible austenitic stainless steels. Wear, 239, p. 48-58, 2000.

8. GAVRILJUK, V. Nitrogen in iron and steel. ISIJ Int., v. 36, n. 7, p.738-745, 1996.

9. BERNS H. Manufacture and application of high nitrogen steels. ISIJ Int., v. 36, n. 7, p. 909-914, 1996.

10. TORO, A., ALONSO-FALLEIROS, N., RODRIGUES, D., AMBROSIO FILHO, F., TSCHIPTSCHIN, A. P. $\mathrm{P} / \mathrm{M}$ processing routes of martensitic stainless steels. Trans. Indian Inst. Met., v. 55, n.5, p.481-487, 2002.

11. BERNS, H., SIEBERT, S. Effect of temperature and nitrogen partial pressure on the case hardening with nitrogen. Proceedings of Int. Conf. on High Nitrogen Steels - HNS, 1993, Kiev: Institute of Metal Physics 1993. p. 566571.

12. SIEBERT, S. Randaufsthicken nichtrostender Stähle. Bochum: RuhrUniversity, 1994. (Doctoral thesis).

13. BERNS H, SIEBERT S. High nitrogen austenitic cases in stainless steels. ISIJ Int., v. 36, n. 7, p. 927-931, 1996.

14. BERNS, H., BOUWMAN, J.W., EUL, U., IZAGUIRRE, J., JUSE, R., NIEDERAU, H., TAVERNIER, G., ZIESCHANG, R. Solution nitriding of 
Efeito do nitrogênio na usinabilidade do aço inoxidável austenítico: uma avaliação utilizando...

stainless steels for process engineering. Mat.-wiss. U. Werkstofftech, v. 31, n. 2, p. 152-161, 2000.

15. TORO, A., MISIOLEK, W., TSCHIPTSCHIN, A.P. Correlations between microstructure and surface properties in a high nitrogen martensitic stainless steel. Acta Mater., v. 51, n. 12, p. 33633374, 2003.

16. GARZÓN, C.M., TSCHIPTSCHIN, A.P. Growth kinetics of martensitic layers during high temperature gas nitriding of a ferritic - martensitic stainless steel. Mat. Sci. and Tech., v. 51, n. 12, p. 915-918, 2004.

17. GARZON, C. M., TORO, A., TSCHIPTSCHin, A. P. Microstructure and chemical characterization of high temperature nitrided martensitic stainless steels. Trans. Indian Inst. Met., v. 55, n. 4, p. 255-263, 2002.

18. MESA, D. H., TORO, A., TSCHIPTSCHIN, A. P. The effect of testing temperature on corrosion-erosion resistance of martensitic stainless steels. Wear, v. 255, n. 1-6, p. 139-145.

19. DOS SANTOS, J. F., GARZÓN, C. M., TSCHIPTSCHIN, A. P. Improvement of the cavitation erosion resistance of an AISI 304L austenitic stainless steel by high temperature gas nitriding. Mat. Sci. and Eng.- A, v. 382, n. 1-2, p. 378-386, 2004.

20. VINGSBO, O., HOGMARK, S. Single-pass pendulum grooving - a technique for abrasive testing. Wear, v. 100, n. 1-3, p. 489502, 1984.
21. JIANG, J., YAO, M., SHENG, F., GAO, X. Dynamical analysis of the wear behaviour of steels during the pendulum single particle gouging wear tests. Wear, v. 181-183, n. 5, p. 371-378, 1995.

22. WILLIAMS, J. A. Analytical models of scratch hardness. Tribology Int, v. 29, n. 8, p. 675-694, 1996.

23. HU, W., LI, S., LI, S., SUN, X., GUAN, H. Determination of dynamic mechanical properties of metals from single pendulum scratch tests. Tribology Int., , v. 32, n. 3, p. 153-160, 1999.

24. PARO, J., HANNINEN, H., KAUPPINEN, V. Tool wear and machinability of X5 CrMnN 188 stainless steels. J. Mater. Process Tech., 119, p. 14-20, 2001.

25. OLIVER, W. C., PHARR, G. M. An improved technique for determining hardness and elastic-modulus using load and displacement sensing indentation experiments. J. Mater. Res., v. 7, n. 6, p.1564-1583, 1992.

26. MALZBENDER, J., DE WITH, G. Indentation loaddisplacement curve, plastic deformation, and energy. J. Mater. Res., , v. 17, n. 2, p. 502-511, 2002.

27. LIANG, Y. N., LI, S. Z., LI, D. F., LI, S. Some developments for single-pass pendulum scratching. Wear, v. 199, n. 1, p. 66-73, 1996.

28. VÉLEZ, J. M., TANAKA, D. K., SINATORA, A., TSCHIPTSCHIN, A. P. Evaluation of abrasive wear of ductile cast iron in a single pass pendulum device. Wear, v. 251, n. 1-12, p. 1315-1319, 2001.

Artigo recebido em 30/07/2006 e aprovado em 05/10/2006.
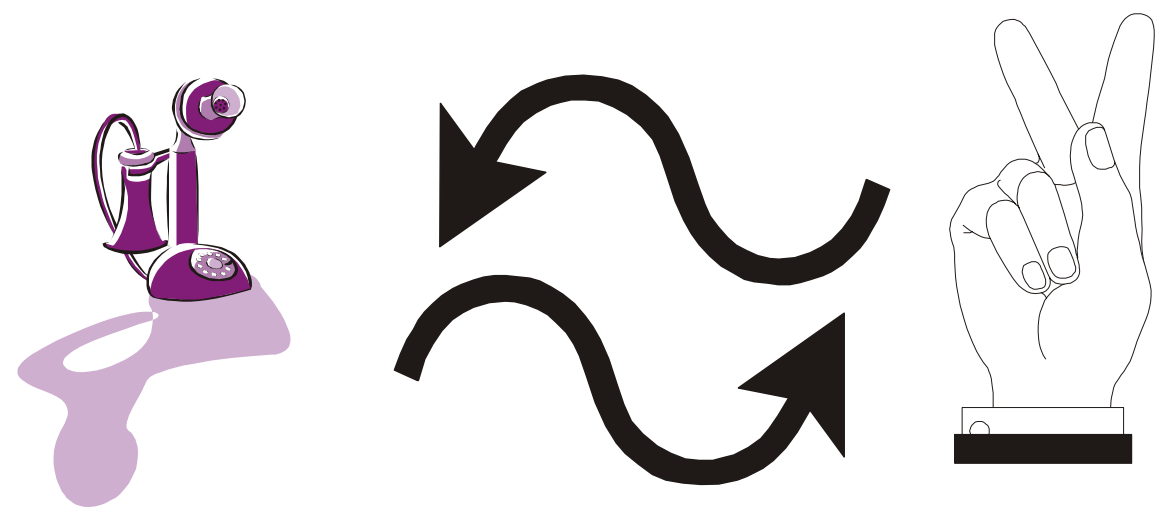

Se é assim que você se comunica com sua revista técnica... Está na hora de você mudar. REM - Revista Escola de Minas a mais antiga revista técnica do setor mínerometalúrgico da América do Sul wWw.rem.com.br 